\title{
A FLIPPED CLASSROOM MODEL FOR A BIOSTATISTICS SHORT COURSE
}

\author{
JACQUELINE E. MCLAUGHLIN \\ UNC Eshelman School of Pharmacy, UNC Chapel Hill, North Carolina \\ jacqui_mclaughlin@unc.edu \\ ISABELL KANG \\ UNC Eshelman School of Pharmacy, UNC Chapel Hill, North Carolina \\ isabell_kang@unc.edu
}

\begin{abstract}
Effective pedagogical strategies are needed to improve statistical literacy within health sciences education. This paper describes the design, implementation, and evaluation of a highly interactive two-week biostatistics short course using the flipped classroom model in the United States. The course was required for all students at the start of a doctoral degree program with the goal of standardizing student preparation, contextualizing biostatistics to healthcare, and identifying students needing additional help. We focused on basic concepts and methods, their application to healthcare, selection of statistical procedures, and results interpretation. Data indicate that students were actively engaged, perceived the course as useful, and experienced learning gains. After the course, students indicated that they better understood the relevance and applicability of biostatistics and were motivated to learn more.
\end{abstract}

Keywords: Statistics education research; Active learning; Constructive alignment

\section{INTRODUCTION}

The appropriate use and interpretation of biostatistics is an essential competency across the health sciences. Proper knowledge of statistics is vital to a wide range of clinical decision-making and healthcare research. In health sciences education, biostatistics is a widely taught topic with applications and accreditation requirements across varied disciplines, including medicine, pharmacy, dentistry, and public health (e.g., Accreditation Council for Pharmacy Education, 2016; Commission on Dental Accreditation, 2015; Council on Education for Public Health, 2011). A recent report from the Association of American Medical Colleges and the Howard Hughes Medical Institute emphasized reading and critiquing literature based on statistical inference and experimental design as a foundation for future physicians (AAMC-HHMI, 2009). Understanding how to design and implement biostatistics curricula to best position students for success is essential amid ongoing changes in education and increased emphasis on evidence-based medicine (Baldi \& Utts, 2015).

Despite the apparent importance of statistics to the health sciences, it remains a challenge to teach (e.g., Bush, Daddysman, \& Charnigo, 2014). In recent years, contemporary recommendations, such as the Guidelines for Assessment and Instruction in Statistics Education (GAISE) have placed a greater emphasis on statistical literacy that empowers students not only to understand statistical concepts but also to critically evaluate

Statistics Education Research Journal, 16(2), XX-XX, http://iase-web.org/Publications.php?p=SERJ

(C) International Association for Statistical Education (IASE/ISI), November, 2017 
and make decisions based on quantitative information (American Statistical Association, 2016). These recommendations provide a framework for redesigning introductory biostatistics, with an emphasis on student-centered strategies that engage students in active learning during class and highlight statistical applications as opposed to calculations (Franklin \& Garfield, 2006). Rethinking pedagogical strategies for teaching biostatistics and identifying new models that actively engage and encourage students to further develop quantitative thinking skills could be an important step toward advancing student development of core statistical competencies.

Emerging pedagogical models that emphasize active learning in the classroom, such as the flipped classroom (Khanova, Roth, Rodgers, \& McLaughlin, 2015), may provide effective solutions for developing student-centered statistics instruction. In the flipped model, instructors select and provide pre-package content for students to learn on their own so that class time can be dedicated to student-centered learning activities, like problembased learning and inquiry-oriented strategies (Bergmann \& Sams, 2012; Deslauriers, Schelew, \& Wieman, 2011; Lage, Platt, \& Treglia, 2000; McLaughlin et al., 2014). To facilitate learning, instructors guide students to the content, organize interactive experiences, challenge students to think creatively, and provide expert insight and feedback.

Although descriptions of active learning strategies in statistics education are wellestablished (e.g., Keeler \& Steinhorst, 1995; Vaughn, 2009), a small but growing body of literature examines the use of the flipped model for teaching statistics. McGraw and Chandler (2015), for example, reported improved student perceptions and in-class quiz performance in a semester-long flipped biostatistics classroom that used pre-recorded videos for preclass learning and problem sets during class. Similarly, improved student views toward the flipped classroom were reported for a semester-long actuarial course in business (Butt, 2014) and an undergraduate statistics course in psychology (Wilson, 2013). Wilson also reported improved student exam scores in a flipped statistics classroom when compared to exam scores in a traditional lecture format. Within the context of biostatistics, the flipped classroom can provide opportunity for thinking critically about the use and interpretation of statistics, such as understanding foundational terms and concepts, critiquing data quality, and interpreting applied statistical methods.

To date, the research examining student-centered pedagogical models for teaching statistics generally describe semester-long courses, leaving a sizable gap concerning short courses. Short courses (also called bridging courses or boot camps) are brief, intensive curricula commonly designed to increase knowledge, boost confidence, facilitate academic and social transitions, and enhance student preparation for more advanced impending coursework. To date, short courses have been described in various formats across a number of disciplines (Gordon \& Nicholas, 2013; Teo, Harleman, O'Sullivan, \& Maa, 2011; Wayne, et al., 2014; Youl, et al., 2005). In undergraduate education, for example, courses have focused on helping incoming students transition into the college environment and coursework (Gordon \& Nicholas, 2013; Read, George, Masters, \& King, 2004; Youl et al., 2005). Gordon and Nicholas (2013) describe a mathematics bridging course that helped students develop strategies for learning mathematics, extend skills in thinking and reasoning, and transition into higher education. In a seven day intensive chemistry course, Youl and colleagues (2005) found that the course effectively addressed knowledge deficits and improved student confidence. In professions education, short courses can help students transition from a degree program into the workplace or postgraduate training (e.g. a fourth year capstone to assess clinical readiness) (Teo, Harleman, O'Sullivan, \& Maa, 2011; Wayne et al., 2014). Wayne and colleagues (2014), for example, found that a 16-hour "boot camp" for students entering medical residency boosted various clinical skills whereas Teo 
and colleagues (2011) reported high satisfaction and perceived preparedness from a medical residency transition course. Though largely unexamined, short courses may also be relevant for students transitioning into advanced degree programs, as students often enroll with an array of skills acquired along varying timelines from diverse experiences, disciplines, industries, cultures, and prior institutions.

Specifically, short courses in statistics are commonly used as refreshers for practitioners and graduate students (Ambrosius \& Manatunga, 2002). They are often commercialized, offered independently from a degree curriculum, and provided at a cost to participants. The format of these courses vary widely, ranging from reviewing basic statistics (e.g., Cornell, Randles, \& Vining, 1995) to learning advanced statistical methods (e.g., Birch, 1995) and often include content about study design (e.g., Windish, 2011). Examples of biostatistics short courses described in the literature include an 8 hour workshop from Turner et al. (2016), a 10-hour short course from Freeman, Collier, Staniforth, and Smith (2008), and a 12-hour short course from Ambrosus and Manatunga (2002). Most commonly, biostatistics short courses are structured in a traditional lecture format, with class time comprised largely of lectures and homework assigned for students to complete after class. One departure from the traditional approach is described by O'Brien Bowling, Mendencorp, Piedmonte, and Kutner (1995), in which students are assigned readings prior to class and engaged in discussions during class time

Numerous calls for change in statistics instruction emphasize the need for more student-centered pedagogy. A growing body of research also points to the benefits short courses for bridging the academic gap between two educational environments or programs (Gordon \& Nicholas, 2013; Teo et al., 2011). Examining the design and implementation of a student-centered statistics short course for students transitioning into a doctoral degree program is an important step toward understanding how to help students with this type of content in an advanced degree curriculum. The purpose of this paper is to describe the design and implementation of a two-week biostatistics course conceptualized with constructive alignment principles (Biggs, 1996) and operationalized with the flipped classroom format. Using a single cohort pre-post study design, this paper describes student performance, perception, and engagement in the course. Although this was a short course, the model outlined here may be relevant for other courses or programs in health sciences and education.

\section{METHOD}

\subsection{COURSE DESIGN}

The UNC Eshelman School of Pharmacy consists of approximately 120 full-time faculty and 620 students enrolled in a four year doctor of pharmacy (PharmD) degree program at two campuses in Chapel Hill and Asheville, North Carolina. In Fall 2015, the school implemented a required pharmacy bridging short course for all newly enrolled students prior to matriculation into foundational pharmacy coursework in year 1 of the degree program. The biostatistics short course was one part of the five-topic pharmacy bridging course offered for the first time in Fall 2015 as a part of the School's transformed curriculum (Roth et al., 2014). Biostatistics met nine times over the course of two weeks for 50 minutes each whereas other topics in the short course (i.e., biochemistry, organic chemistry, applied math, physiology) met at separate times of the day over the same time period. A subset of students participated synchronously via video teleconference (VTC) from a single classroom at the School's satellite campus in Asheville. Students connected 
synchronously were able to participate in all class activities and interact with the instructor to ask or answer questions as needed.

Because statistics is a pre-requisite for admission into the UNC Eshelman School of Pharmacy PharmD degree program, incoming students were expected to have a basic understanding of key statistical concepts. However, the scope and depth of student knowledge can vary widely based on institutional differences, discipline context (i.e., biostatistics, applied statistics, psychology/psychometrics), and student experiences. As such, this course was designed to provide instruction on basic biostatistics concepts applied to healthcare-specific problems in an effort to standardize student preparation for the curriculum, contextualize biostatistics to pharmacy and healthcare, and identify students needing additional support or instruction as early as possible.

Upon entry into the foundational courses immediately following the short course, students were expected to (a) understand basic statistical methods described in the literature, and (b) engage in a fruitful collaborative relationship with an applied statistician. Biostatistics was specifically designed to focus on basic concepts and statistical methods and their application to problems in the health sciences, including understanding data distributions, evaluating the appropriateness of an analysis method, selecting appropriate statistical procedures, and interpreting results. To that end, this course focused on the breadth of statistical ideas and methods at the expense of depth in any one area of biostatistics. Statistical software packages were not utilized or discussed in detail during this course and students were not required to perform any statistical calculations. Further, the terminology and statistical methods described in the biostatistics short course aligned with content covered in more depth in the Evidence-Based Practice course in the first year of the curriculum.

This course was designed using constructive alignment principles, which uses constructivism as a framework to guide decision-making in deriving curriculum objectives, deciding teaching/learning activities, and assessing student performance (Biggs, 1996). By using constructivism, which emphasizes the learner's process for creating meaning, the course design should elucidate learner meaning and cognition through appropriately related objectives, activities, and assessment. As noted by Biggs (1996), "a performative notion of understanding enables teachers to specify the things students need to be able to do in order to demonstrate particular levels of understanding" (p. 353).

Prior to the start of the course, students were provided with a detailed syllabus that described course learning objectives, pre-class learning requirements, in-class active learning format, and assessment plan. Course learning objectives for biostatistics included:

- Explain why biostatistics is important to pharmacists.

- Define the basic characteristics of data and distinguish between different types of variables;

- Understand population and samples; contrast descriptive statistics and inferential statistics;

- Describe common data distributions and understand the implications of normal and non-normal distributions;

- Identify various measurement considerations, including types of error, alpha, bias, validity, reliability, and power;

- Define probability, odds ratio, and risk assessment;

- Select appropriate tests to compare outcomes for sample means or frequencies; and

- Describe regression-based tests (e.g., linear, logistic, multi-level).

Prior to each class period, students were expected to complete a self-paced online lesson developed by the course instructor. There were nine online lessons, one for each class period, and each online lesson took an estimated 30 minutes to complete. Each lesson 
was text-based with some embedded graphics and organized into the following sections: 1) "Introduction," with learning objectives for the lesson; 2) "Terminology," with definitions for key terms; 3) "Basic Concepts," with descriptions of core ideas; 4) "Reported Results," including graphs and tables from published literature; and 5) "Assessment," providing 5-6 optional multiple-choice assessment questions (Figure 1). Students could visit and complete the online lesson and optional assessment questions multiple times, as needed. The online lessons were specifically designed to prepare students to participate in active-learning exercises about terminology, foundational concepts, and basic applied biostatistics during class. The template for the online pre-class learning module was developed by the School's Educational Design and Innovation (EDI) group, who created the platform with the direction of the biostatistics instructor using a combination of software, including Adobe Master Suite version CS6 (Adobe Systems, 2012) and MySQL Release 5.8 (Oracle Corporation, 2011). The biostatistics instructor inputted all content (e.g. text, graphics, tables, assessment questions) into the template, which was further refined by the EDI group for visual appeal. There were no required textbooks or additional readings, although additional supplemental resources and references were identified for students. Internet access (high-speed preferred) was required to access the lessons and access to the online lessons was limited to personnel with a university login and password.

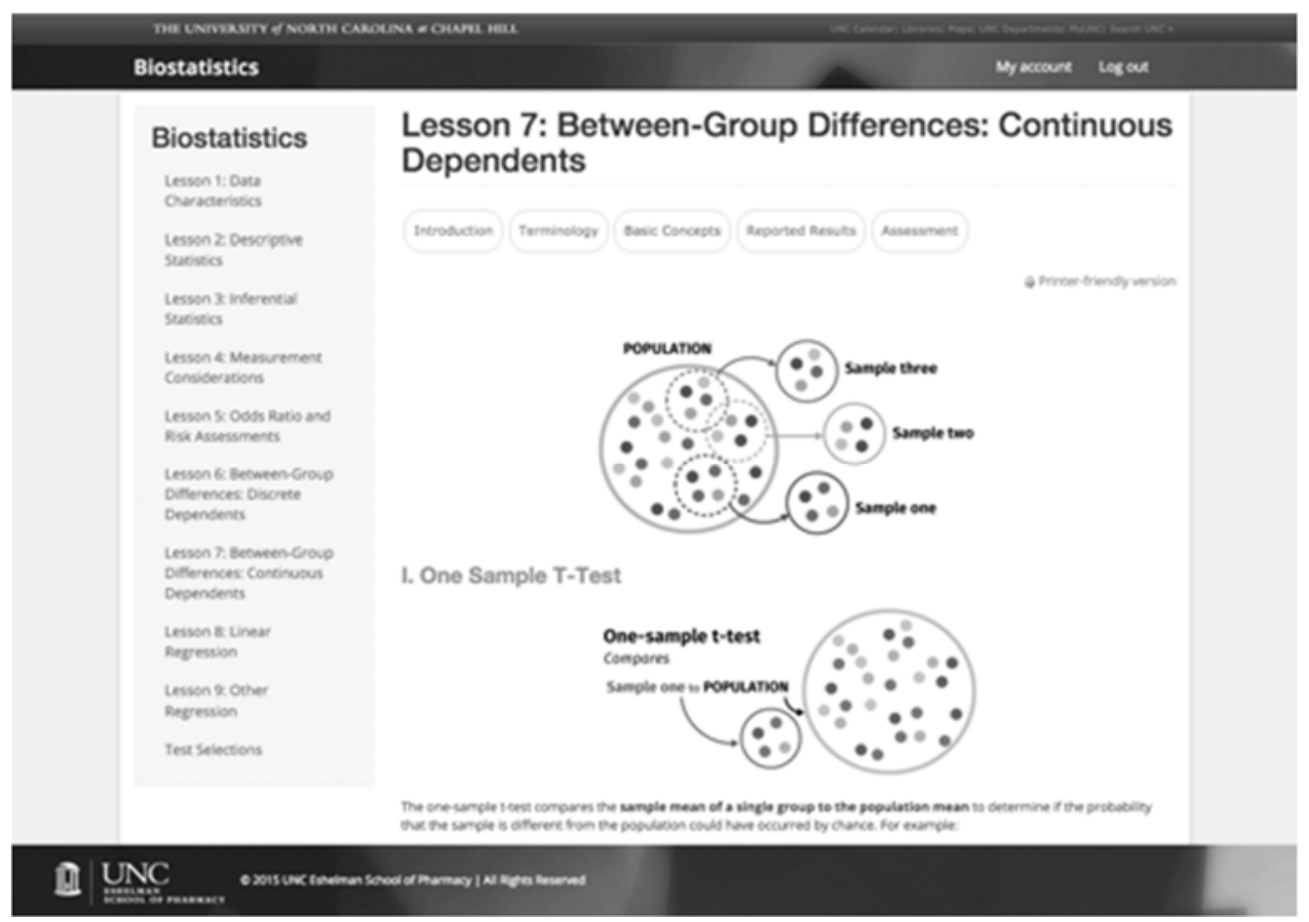

Figure 1. Example webpage from an online biostatistics learning module used for pre-class preparation

Class time was structured to reinforce foundational concepts through active learning, assessment, and short lectures, as needed. Active learning exercises were selected to align with the online pre-class lessons and generally followed the basic format: 
- 5 minute introduction: instructor oriented students to the topic of the day and answered questions about prior class sessions;

- 10 minute term talk: instructor provided a vocabulary list of approximately 8 terms for students to discuss and define in small groups. Any unclear terms were clarified by the instructor as needed at the end of the exercise (emphasized terminology);

- 10 minute clickers (also called audience response system questions): students were asked to answer 4-5 multiple choice questions about foundational concepts (emphasized basic concepts);

- 20 minute graphix case study: students were provided a graphical representation of biostatistics results from health sciences literature (e.g., tables, figures, graphs) and asked to discuss the statistical results in small groups and answer probing questions by the instructor (emphasized interpretation of reported results and exposed students to standard biostatistics reporting as seen in the literature);

- 5 minute wrap up

\subsection{EVALUATION}

A single cohort pre-post study design was used to evaluate the course. In fall of 2015 , 153 students enrolled in the course with 128 of those on the main campus in Chapel Hill, $\mathrm{NC}$ and 25 of those on the satellite campus in Asheville, NC. For each student, data collection included engagement with the online lessons (e.g., number of assessment questions answered, performance on assessment questions), participation in class (e.g., number of days using clickers), and performance on a pre-test prior to the short course and a final examination at the end of the short course. All assessments were written by the instructor and reviewed by a support team for clarity and appropriateness. Items on the pretest and final examination were mapped to the course learning objectives to ensure that each objective was assessed as part of the tests. All pre-test and final examination items were multiple choice and scored by electronic software. The pre-test and final examination were similar in content and format and both were scored out of 100 points. Students' final short course grades were determined by participation ( $15 \%$, as indicated by completion of the pre-test prior to the first day of class and in-class clicker questions) and the final examination (85\%). In addition, students were asked to complete a course evaluation, which was optional and anonymous. Course evaluation items were standardized items used by the School to assess all courses in the curriculum and were measured on a 5-point scale unless otherwise indicated. Continuous data are summarized by the mean and standard deviation $(S D)$. Paired $t$-tests examined differences in the pre- and post-test. A 95\% confidence interval (CI) was computed for mean differences in the pre-test and final examination. This study was determined to be exempt from further review by the University of North Carolina Institutional Review Board. All data analysis was conducted in SPSS for Mac, Version 23.

\section{RESULTS}

Of the 153 students enrolled in the course, $68 \%$ were female, $12 \%$ were Black/African American, 62\% were White/Caucasian, 23\% were Asian, and 78\% earned a Bachelor's degree prior to enrolling in pharmacy school. Table 1 shows student engagement with online modules and in-class clicker questions. Completion of optional assessment questions embedded in the online pre-class learning module ranged from $77.8 \%$ of students 
for lesson 9 to $98.0 \%$ of students for lesson 2. One-hundred and twenty three students responded to clicker questions for all 6 days for which clicker data is available and the remaining 30 students clicked in for 5 days. Overall, the average correct score for the inclass clicker questions across all 9 class sessions was 77.5 (15.8) out of 100.

Table 1: Student engagement with online modules \& in-class clicker questions $(n=153)$

\begin{tabular}{lllllll}
\hline $\begin{array}{l}\text { Lesson/Class } \\
\text { Period }\end{array}$ & $\begin{array}{l}\text { Completed Online Pre-Class } \\
\text { Assessment }\end{array}$ & $\begin{array}{l}\text { Online } \\
\text { Assessment }\end{array}$ & $\begin{array}{l}\text { Pre-Class } \\
\text { Score }\end{array}$ & $\begin{array}{l}\text { Used } \\
\text { Class }\end{array}$ & Clicker & In \\
\hline 1 & $n$ & $\%$ & Mean & SD & $n$ & $\%$ \\
\hline 2 & 147 & 96.1 & 88.7 & 12.2 & 123 & 80.4 \\
3 & 150 & 98.0 & 94.3 & 9.9 & 148 & 96.7 \\
4 & 136 & 88.9 & 92.8 & 12.1 & 148 & 96.7 \\
5 & 135 & 88.2 & 90.2 & 14.8 & NA & NA \\
6 & 138 & 90.2 & 91.2 & 12.5 & NA & NA \\
7 & 134 & 87.6 & 86.1 & 16.6 & 153 & 100.0 \\
8 & 125 & 81.7 & 86.4 & 15.9 & 153 & 100.0 \\
9 & 129 & 84.3 & 89.0 & 11.7 & 153 & 100.0 \\
\hline
\end{tabular}

${ }^{*}$ Some students had not yet received their clickers for Class 1; NA indicates data not recorded due to technological difficulties, however questions were still posed and answered in class and students were unaware that the data were not recorded.

Course evaluation results ( $n=100$, response rate $65 \%$ ) suggested that the biostatistics short course was generally well-received by students (Table 2). As seen in Table 2, most students agreed or strongly agreed that the course increased their desire to continue learning about this material (72\%), helped them understand basic concepts more clearly (95\%), and helped them understand the relevance and applicability of biostatistics to pharmacy and

Table 2: Course evaluation responses for the biostatistics short course $(n=100)$

\begin{tabular}{lll}
\hline Course evaluation item ${ }^{\mathrm{a}, \mathrm{b}}$ & Agree (\%) & Strongly Agree (\%) \\
\hline $\begin{array}{l}\text { Biostatistics content was clearly related to the overall } \\
\text { learning outcomes. }\end{array}$ & 36 & 60 \\
$\begin{array}{l}\text { Biostatistics was well organized. } \\
\begin{array}{l}\text { Biostatistics activities (e.g., in-class exercises, assignments) } \\
\text { helped me better understand and apply the material. }\end{array}\end{array}$ & 30 & 70 \\
$\begin{array}{l}\text { The assessments gave me an opportunity to demonstrate } \\
\text { what I had learned about Biostatistics. }(n=97)\end{array}$ & 37 & 57 \\
$\begin{array}{l}\text { The amount of work required was appropriate to the overall } \\
\text { learning outcomes. ( } n=99)\end{array}$ & 30 & 66 \\
$\begin{array}{l}\text { Biostatistics increased my desire to continue learning about } \\
\text { this material. }\end{array}$ & 32 & 40 \\
$\begin{array}{l}\text { Biostatistics presented a high level of intellectual challenge. } \\
(n=99)\end{array}$ & 35 & 27 \\
$\begin{array}{l}\text { Biostatistics helped me understand basic concepts more } \\
\text { clearly. }\end{array}$ & 35 & 60 \\
$\begin{array}{l}\text { Biostatistics helped me understand the relevance and } \\
\text { applicability of this to pharmacy and health care. }(n=99)\end{array}$ & 33 & 62 \\
$\begin{array}{l}\text { a Items were measured on a 5-point scale: (1) strongly disagree, (2) disagree, (3) neither agree or } \\
\text { disagree, (4) agree, and (5) strongly agree. }\end{array}$ & \\
b $n=100$ unless noted otherwise
\end{tabular}


health care (95\%). Eighty percent indicated that, overall, the course was very good (38\%) or excellent $(42 \%)$. Ninety-nine percent agreed or strongly agreed that the instructor was an effective teacher and $99 \%$ agreed or strongly agreed that the instructor actively engaged students in the classroom. When asked how much time was spent preparing for class on a daily basis, $68.6 \%$ indicated 30 minutes or less, $22.3 \%$ indicated $31-60$ minutes, and $1.4 \%$ indicated more than one hour.

Students performed significantly better on the final biostatistics examination than the pre-test $(86.1(9.4)$ vs $59.0(14.2), 95 \%$ CI $(24.2,29.8), p<.001)$, with a mean $(S D)$ difference of 27.1 (16.2). As seen by the distribution of scores in the pre-test and final examination in Figure 2, students performed markedly better on the final examination, with all students scoring at or above a 50 .

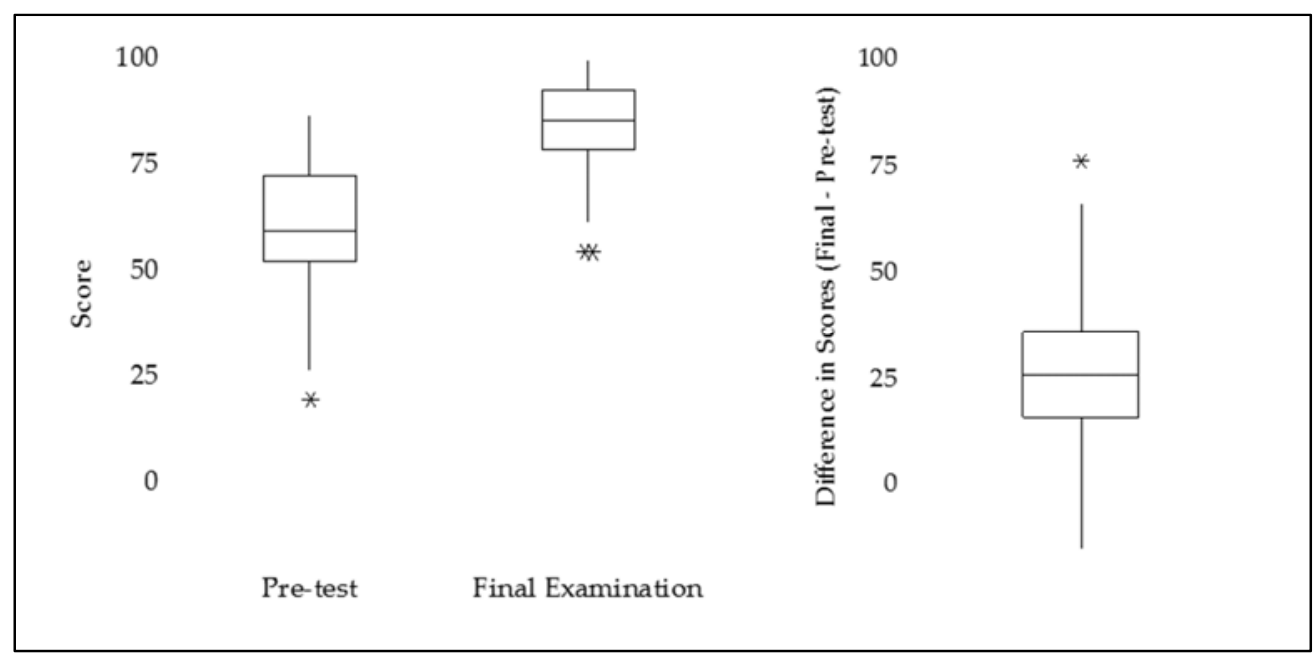

Figure 2. Box plots for the pre-test, final examination, and differences between the two for a biostatistics short course in 2015

\section{DISCUSSION}

Given the importance of biostatistics to patient care and the challenge of teaching this material to students, it is crucial to identify effective pedagogical strategies for improving statistical literacy in health professions education. Within the context of a biostatistics short course, it is not feasible to teach students how to conduct all of the biostatistics methods that are relevant to pharmacy and healthcare on their own. However, a short course can provide a mechanism for improving student understanding of core statistical concepts, standardizing student preparation for the curriculum, contextualizing statistics to healthcare, and identifying students that may warrant additional support or instruction as early as possible.

In general, this study suggests that a biostatistics short course can add value to a student's educational experience at the start of a health professions degree program. Unlike most statistics short courses, which are designed and offered at a separate cost, this course was built into the degree program, as advocated for by Ambrosious and Manatunga (2002). However, unlike the service course offered by Ambrosious and Manatunga, our short course was required of all students enrolled in the curriculum. Perception, performance, and engagement data demonstrate that students actively participated in the pre-class and in-class activities, perceived the course as useful, and experienced learning gains. Students 
indicated that they understood the relevance and applicability of biostatistics to pharmacy and health care and were motivated to learn more about statistics after participating in the short course. Although nine hours of instruction limits the depth and scope of material that can be covered in the course, this appeared to be sufficient for meeting the goals of the course, namely to review prerequisite concepts and their application to problems in the health sciences. This goal and time commitment aligns with other biostatistics short courses described in the literature (e.g., Ambrosious \& Manatunga, 2002; O'Brien, et al., 1995; Robertson, Tilford, \& Shema, 1995).

When examined in the context of previously published reports of biostatistics short courses, this appears to be the first reporting of a statistics short course explicitly designed using a flipped classroom format. Although the study design limits our ability to determine the relative efficacy of the flipped format compared to other pedagogical approaches, this report suggests that students (a) perceived the core elements of the flipped class favorably (e.g., pre-class material, in-class activities, assessments), (b) were highly engaged with preclass and classroom activities, and (c) achieved higher scores at the conclusion of the course. These results support emerging literature that describes the perceived benefits of the flipped classroom, including improved performance and favorable perceptions (e.g., Butt, 2014; McGraw \& Chandler, 2015; Wilson, 2013). In our biostatistics short course, course developers used emerging guidelines for best practice in flipped classroom design, namely: aligning pre-class material, in-class activities, and assessments; clearly communicating purpose and expectations; and engaging students with the content, instructor, and one another during class (Khanova et al., 2015). This use of constructive alignment emphasized activities, materials, and assessments that were developed and implemented so that students could construct knowledge in an organized and sequenced way. The flipped approach also reinforces numerous calls for reform in medical and health sciences education concerning the ways in which students are engaged in learning in the health sciences (e.g., Irby, Cook, \& O'Brien, 2010; Speedie et al., 2012).

Although the data indicated that students were highly engaged and motivated in this model, it is likely that other student-centered approaches could also be successful. A growing body of flipped classroom research describes wide variability in the operationalization of flipped classrooms that promote improved outcomes (e.g., Deslauriers et al., 2011; McLaughlin \& Rhoney, 2015). Whereas the online pre-class learning module was designed specifically for this course, alternative resources such as textbooks, Khan Academy videos (see https://www.khanacademy.org/), or journal articles may also serve as viable pre-class preparatory tools. Further, there are a wide range of active learning exercises that can foster complex problem-solving and critical thinking that might also be appropriate for engaging students in biostatistics (Prince, 2004). Given these points, future research should examine the extent to which any gains associated with a flipped classroom are attributed to the thoughtful design and implementation of the course, rather than the specific activities and modalities employed.

Using sound instructional design principles partnered with effective pedagogical practices that emphasize critical thinking with contemporary contextual significance requires thoughtful planning and ongoing refinement. Moving forward, refinements will be made to the course based on student feedback and instructor experiences. The first few lessons will be condensed to allow more time for complex statistical concepts and methods, such as multilevel models, toward the end of the course. In addition, online material in the pre-class learning module will undergo a series of edits to better reflect contemporary and emerging topics in health care and meet the needs of incoming classes. Additional resources (e.g., journal articles) that elucidate statistical concepts and their applications will also be identified and made available to students. Evaluation of student performance, 
engagement, and perceptions will continue as a mechanism for ensuring that subsequent offerings of the course remain relevant, sustainable, and effective.

This course and its evaluation represent an important first step toward understanding the statistical literacy of our students as they prepare for subsequent coursework in the curriculum. However, future research should be designed to elucidate specific aspects of the instructional method and format that impact student learning. The study design used here did not include a comparison group and provides no basis for evaluating the relative efficacy of the proposed model. For example, further research separating elements of the short course and the flipped classroom and using controls for comparison could help identify those aspects of the model related to outcomes of interest. In addition, this course was designed to cover core concepts presumably covered in required prerequisite coursework, leaving it unclear how this model would impact learning of new or unfamiliar statistics concepts. Using more rigorous approaches for evaluation will be critical for better understanding and advancing statistics education in this context.

Additional limitations to this study warrant attention. Due to technological difficulties, in-class student engagement data (i.e., clicker responses) were missing for a couple of lessons. Although a course participation grade incentivized engagement in this activity, high rates of completion for the optional pre-class assessment questions also suggest that students were highly engaged. In addition, only $65 \%$ of students responded to the course evaluation, which may have biased evaluation results. As this is the first offering of the course, only one year of data is currently available; subsequent course offerings will provide opportunities to more rigorously assess the validity and reliability of the course assessments along with the impact of course design and implementation. In addition, research concerning retention of material in subsequent courses in the curriculum will provide insight into the utility and effectiveness of the biostatistics short course as it relates to other aspects of the PharmD curriculum and help further inform curriculum requirements. Despite these limitations, this paper offers a model for teaching an engaging biostatistics course that seems to enable students to understand the core tenets of biostatistics while learning their importance to health professions and clinical decision making.

\section{CONCLUSIONS}

Developing new strategies for teaching statistics amid ongoing changes in education and healthcare is critical. A highly interactive two-week biostatistics short course was developed to review basic biostatistics concepts at the onset of a doctoral degree program. This course was designed using constructive alignment principles and a student-centered flipped format as a means of engaging students in active and applied learning during classtime. The results from this study suggest that this approach allows for student engagement and improved assessment scores. Students generally perceived the course favorably. The process illustrated in this paper reflects the operationalization of a biostatistics short course, but the model described here may be translated to other courses or programs in health sciences education.

\section{ACKNOWLEDGEMENTS}

The authors would like to thank The Carolina Partnership and The Pharmacy Network Foundation, Inc. for generous support of The Academy and the Educational Renaissance initiative in the UNC Eshelman School of Pharmacy. The authors would also like to thank

Nicki Pinelli, Greene Shepherd, Scott Singleton, and Heyward Hull for their help with the 
design and implementation of this course. In addition, we would like to acknowledge Catherine MacAllister, Jason Whitley, and other members of The Academy and the UNC Eshelman School of Pharmacy Education Design and Innovations group for providing critical support in the design and implementation of the online learning module. We would also like to thank the SERJ Associate Editor who helped us with the analysis and the generation of the plots.

\section{REFERENCES}

Accreditation Council for Pharmacy Education. (2016). Accreditation standards and key elements for the professional program in pharmacy leading to the doctor of pharmacy degree.

[Online: https://www.acpe-accredit.org/pdf/Standards2016FINAL.pdf]

AAMC-HHMI Committee. (2009). "Scientific Foundations for Future Physicians."

[Online: https://www.aamc.org/download/271072/data/scientificfoundationsforfuturephysicians.pdf]

Ambrosious, W. T., \& Manatunga, A. M. (2002). Intensive short courses in biostatistics for fellows and physicians. Statistics in Medicine, 21(18), 2739-2756.

American Statistical Association. (2016). Guidelines for assessment and instruction in statistics education. Alexandria, VA: author.

[Online: http://www.amstat.org/asa/files/pdfs/GAISE/GaiseCollege_Full.pdf]

Baldi, B., \& Utts, J. (2015). What your future doctor should know about statistics: Mustinclude topics for introductory undergraduate biostatistics. The American Statistician, 69(3), 231-240.

Bergmann, J., \& Sams, A. (2012). Flip your classroom: Reach every student in every class every day. Washington, DC: International Society for Technology in Education.

Biggs, J. (1996). Enhancing teaching through constructive alignment. Higher Education, 32(3), 347-364.

Birch, J. B. (1995). Ten suggestions for effectively teaching short courses to heterogeneous groups. The American Statistician, 49(2), 190-195.

Bush, H. M., Daddysman, J., \& Charnigo, R. (2014). Improving outcomes with Bloom's Taxonomy: From statistics education to research partnerships. Journal of Biometrics Biostatistics, 5, e130. doi: 10.4172/2155-6180.1000e130

Butt, A. (2014). Student views on the use of a flipped classroom approach: Evidence from Australia. Business Education \& Accreditation, 6(1), 33-44.

Commission on Dental Accreditation. (2015). Accreditation standards for advanced specialty education programs in dental public health. Retrieved from http://www.ada.org/ /media/CODA/Files/dph.ashx

Cornell, J. A., Randles, R. H., \& Vining, G. G. (1995). Challenges in teaching short courses by an academic department: The University of Florida experience. The American Statistician, 49(2), 195-200.

Council on Education for Public Health. (2011). Accreditation criteria. Retrieved from http://ceph.org/assets/PHP-Criteria-2011.pdf

Deslauriers, L., Schelew, E., Wieman, C. (2011). Improved learning in a large-enrollment physics class. Science, 332(6031), 862-864.

Franklin, C., \& Garfield, J. (2006). Guidelines for statistics education endorsed by ASA Board of Directors. Amstat News (Education), 348.

Freeman, J. V., Collier, S., Staniforth, D., Smith, K. J. (2008). Innovations in curriculum design: A multi-disciplinary approach to teaching statistics to undergraduate medical students. BMC Medical Education, 8(28). doi: 10.1186/1472-6920-8-28 
Gordon, S., \& Nicholas, J. (2013). Students' conceptions of mathematics bridging courses. Journal of Further and Higher Education, 37(1), 109-125.

IBM SPSS Statistics for Mac (Version 23.0) [Computer program]. Armonk, NY: IBM Corp.

Irby, D. M., Cooke, M., \& O'Brien, B. C. (2010). Calls for reform in medical education by the Carnegie Foundation for the Advancement of Teaching: 1910 and 2010. Academic Medicine, 85(2), 220-227.

Keeler, C. M., \& Steinhorst, R. K. (1995). Using small groups to promote active learning in the introductory statistics course: A report from the field. Journal of Statistics Education, 3(2), 1-8.

[Online: https://ww2.amstat.org/publications/jse/v3n2/keeler.html]

Khanova, J., Roth, M. T., Rodgers, J. E., \& McLaughlin, J. E. (2015). Student experiences across multiple flipped classrooms in a single curriculum. Medical Education, 49(10), $1038-1048$.

Lage, M. J., Platt, G. J., \& Treglia, M. (2000). Inverting the classroom: A gateway to creating an inclusive learning environment. The Journal of Economic Education, 31(1), $30-43$.

McGraw, J. B., \& Chandler, J. L. (2015). Flipping the biostatistics classroom, with a twist. The Bulletin of the Ecological Society of America, 96(2), 375-384.

McLaughlin, J. E., \& Rhoney, D. H. (2015). Comparison of pre-class preparatory learning tools: Findings from a flipped neurology lecture. Currents in Pharmacy Teaching and Learning, 7(1), 12-19.

McLaughlin, J. E., Roth, M. T., Glatt, D. M., Gharkholonareh, N., Davidson, C. A., Griffin, L. M.,...Mumper, R. J. (2014). The flipped classroom: A course redesign to foster learning and engagement in a health professions school. Academic Medicine, 89(2), 236-243.

O’Brien, R. G., Bowling, D. W., Mendencorp, S. V., Piedmonte, M. R., \& Kutner, M. H. (1995). A seminar in clinical biostatistics for established physicians. Proceedings of the ASA Sections on Statistical Education and Teaching Statistics in Health Sciences, (pp. 1-4). Alexandria, VA: American Statistical Association.

Prince, M. (2004). Does active learning work? A review of the research. Journal of Engineering Education, 93(3), 223-231.

Read, J., George, A., Masters, A., \& King, M. (2004). Students' perceptions of their understanding in chemistry 1 for veterinary science. In D. Merrett (Ed.), Proceedings of Scholarly Inquiry into Science Teaching and Learning Symposium (pp. 45-51). Sydney, NSW: UniServe Science.

Robertson, P. K., Tilford, J. M., \& Shema, S. J. (1995). Developing instruction in research skills for pediatric fellows. Proceedings of the ASA Sections on Statistical Education and Teaching Statistic in Health Sciences, (pp. 317-319). Alexandria, VA: American Statistical Association.

Roth, M. T., Mumper, R. J., Singleton, S. F., Lee, C. R., Rodgers, P. T., Cox, W. C., ..., Blouin, R. A. (2014). A renaissance in pharmacy education at the University of North Carolina at Chapel Hill. North Carolina Medical Journal, 75(1), 48-52.

Speedie, M. K., Baldwin, J. N., Carter, R. A., Raehl, C. L., Yanchick, V. A, \& Maine, L. L. (2012). Cultivating "habits of mind" in the scholarly pharmacy clinician: Report of the 2011-2012 Argus Commission. American Journal of Pharmaceutical Education, 76(6), Article S3.

Teo, A. R., Harleman, E., O'Sullivan, P. S., \& Maa, J. (2011). The key role of a transition course in preparing medical students for internship. Academic Medicine, 86(7), 860865. 
Turner, S., Sundaresan, P., Mann, K., Pryor, D., Gebski, V., \& Shaw, T. (2016). Engaging future clinical oncology researchers: An initiative to integrate teaching of biostatistics and research methodology into specialty training. Clinical Oncology, 28(5), 306-316.

Vaughn, B. K. (2009). An empirical consideration of a balanced amalgamation of learning strategies in graduate introductory statistics classes. Statistics Education Research Journal, 8(1), 106-130.

[Online: https://iase-web.org/documents/SERJ/SERJ8(1)_Vaughn.pdf]

Wayne, D. B., Cohen, E. R., Singer, B. D., Moazed, F., Barsuk, J. H., Lyons, E. A., ... McGaghie, W. C. (2014). Progress toward improving medical school graduates' skills via a "boot camp" curriculum. Simulation in Healthcare, 9(1), 33-39.

Windish, D. M. (2011). Brief curriculum to teach residents study design and biostatistics. Evidence Based Medicine, 16(4), 100-104.

Wilson, S. G. (2013). The flipped class a method to address the challenges of an undergraduate statistics course. Teaching of Psychology, 40(3), 193-199.

Youl, D., Read, J., George, A., Masters, A., Schmid, S., \& King, M. (2005). Bridging the gap-student understanding and the chemistry bridging course. Proceedings of Blended Learning in Science Teaching and Learning Symposium (pp. 191-194). Sydney, NSW: UniServe Science.

JACQUELINE E. MCLAUGHLIN

UNC Eshelman School of Pharmacy University of North Carolina at Chapel Hill

329 Beard Hall

Chapel Hill, North Carolina 27599

E-mail: jacqui_mclaughlin@unc.edu

Phone: (919) 966-4557 